\title{
Development of Hydraulic Friction Brake for Railway Rolling Stock* \\ (Part I: Static Behavior of Poppet-Type Brake Pressure Control Valve)
}

\author{
Thum CHENVISUWAT**, Sung-Hwan PARK ${ }^{* * *}$ and Ato KITAGAWA***
}

\begin{abstract}
In this study, a novel hydraulic brake system is proposed in order to increase the reliability of railway brake systems. The reason hydraulic brake systems have not been taken up as a practical railway brake system until now is that the brake pressure control valve inherently has internal leakage and this causes insufficient fail-safe function. Accordingly, We focus on the development of a hydraulic brake pressure control valve (BPC valve) in this study. By virtue of adopting poppet elements in the valve, the braking force is maintained without internal leakage even when the electric power supply fails. The developed BPC valve includes a built-in pressure feedback mechanism and it enables the pressure control function to be maintained when the pressure transducer is broken. The operating principle and wear compensation methods for poppet elements are also examined in this study. The experimental results verify the linearity of static behavior, the stability, and the performance of the valve in maintaining output pressure.
\end{abstract}

Key Words: Railway, Hydraulic Brake, Pressure Control, Poppet Valve, Servomechanism

\section{Introduction}

Recently, electrical railways have adopted a hybrid brake system composed of a mechanical brake (friction brake) and an electrical brake (dynamic brake). The outputs of these brakes are combined to optimize the performance of the brake system ${ }^{(1)}$. The friction brake is a fundamental device for every railway. It is used as a common brake, an emergency brake, and a parking brake as well $^{(2)-(5)}$. The dynamic brake is a new system currently being used in modern electrical railways. The power from braking can be regenerated by the electrical driving motor and fed back to the nearest electrical substation. The per-

* Received 28th November, 2003 (No. 03-4186)

** Department of Mechanical and Control Engineering, Tokyo Institute of Technology, 2-12-1 O-okayama, Megurogu, Tokyo 152-8552, Japan.

E-mail: thum@cm.ctrl.titech.ac.jp

*** Department of Mechanical and Control Engineering, Tokyo Institute of Technology, 2-12-1 O-okayama, Megurogu, Tokyo 152-8552, Japan.

E-mail: shpark@cm.ctrl.titech.ac.jp

**** Department of Mechanical and Control Engineering, Tokyo Institute of Technology, 2-12-1 O-okayama, Megurogu, Tokyo 152-8552, Japan.

E-mail: kitagawa@cm.ctrl.titech.ac.jp formance of the dynamic brake system is not influenced by wear. But, the regenerated power is limited by some factors such as the performance of the substation and the size of electrical transmission lines. Accordingly, its output force and response are insufficient, particularly in both very high-speed and low-speed ranges. Owing to these limitations, the precise braking force is controlled by the friction brake. As the speed of railways increases, braking performance must be improved. The need for a highly responsive braking system has recently increased in order to control the slip rate between the wheel and rail ${ }^{(6),(7)}$. Since the overslip results in a longer braking distance and defects $^{(8)}$ on the wheel, the optimized control of slip rate is required. In order to control slip rate, the variation of adhesion between the wheel and the rail is considered, and any difference between the speed of the vehicle and that of the wheel must be corrected regardless of rail condition. Therefore, a highly responsive braking system is required to implement slip rate control algorithms.

In this study, a focus is given on the control of the friction brake system. Almost every friction brake is composed of a pneumatic system based on the technology of Westinghouse ${ }^{(9)}$. This system can provide both sufficient braking force and highly safe performance with many efficient fail-safe features. However, the system is 
still very large, hard to maintain, and its performance is limited by the compressibility of air. Accordingly, based on the advantages of the hydraulic system such as a high power and a high power density, the use of a brake-bywire (BBW) hydraulic system is proposed in this study in order to improve the performance of braking control, in which a compact hydraulic brake system is installed on each bogie to control the friction brake devices, and the control signals are transmitted by electrical wires instead of long pipelines. The basic concept of a BBW hydraulic system is similar to the fly-by-wire system for flight control $^{(10),(11)}$. Through the use of the BBW hydraulic system, the compact hydraulic brake system unit on a bogie can be easily replaced by a few workers, which also increases the efficiency of maintenance. Some researchers have already reported that the use of the hydraulic system could improve the braking response and reduce the size and weight of the entire brake system ${ }^{(12),(13)}$. In spite of all these highly desirable features of the hydraulic brake system, it was not taken up as practical railway brake system because of the inherent internal leakage characteristic of the BPC valve. This leakage causes insufficient failsafe function. In order to solve this problem, a novel brake pressure control valve (BPC valve) is developed in this study. By virtue of adopting poppet elements in the valve, the braking force is maintained even when the electric power supply fails without internal leakage. The developed BPC valve includes a built-in pressure feedback mechanism and it enables the pressure control function to be maintained when the pressure transducer is broken.

The rest of this paper is organised as follows. The mechanism and operating principle of the developed valve are described in section 2 . The analysis and compensation methods of reducing the actuating force and the effects of wear are discussed in section 3. Experiments performed to verify the validity of the developed valve are presented in section 4. Concluding remarks are made in section 5 .

\section{Nomenclature}

$A_{e A}$ : change in cross-sectional area of the seat of valve $\mathrm{A}, \mathrm{m}^{2}$

$A_{e B}$ : change in cross-sectional area of the seat of valve $\mathrm{B}, \mathrm{m}^{2}$

$A_{s}$ : cross-sectional area of seat, $\mathrm{m}^{2}$

$A_{v}$ : flow passage area of poppet valve, $\mathrm{m}^{2}$

$A_{x}$ : cross-sectional area of control rod, $\mathrm{m}^{2}$

$d_{v}:$ diameter of seat, $\mathrm{m}$

$F_{b l}$ : force of compensation spring, $\mathrm{N}$

$F_{b l 0}$ : initial force of compensation spring, $\mathrm{N}$

$F_{x}$ : operating force of control device, $\mathrm{N}$

$k_{b l}$ : spring constant of compensation spring, $\mathrm{N} / \mathrm{m}$

$k_{s}$ : spring constant, $\mathrm{N} / \mathrm{m}$

$p_{b c}$ : pressure in the chamber of the brake cylinder, $\mathrm{Pa}$

$p_{s}$ : supply pressure, $\mathrm{Pa}$ $p_{t}:$ return pressure, $\mathrm{Pa}$

$q_{A}$ : flow through poppet valve $\mathrm{A}, \mathrm{m}^{3} / \mathrm{s}$

$q_{B}$ : flow through poppet valve $\mathrm{B}, \mathrm{m}^{3} / \mathrm{s}$

$x$ : displacement of the control rod, $\mathrm{m}$

$x_{0 A}$ : initial length of the compressed spring A (at $x=$ $0), \mathrm{m}$

$x_{0 B}$ : initial length of the compressed spring B (at $x=$ $0), \mathrm{m}$

$x_{A}:$ displacement of poppet $\mathrm{A}, \mathrm{m}$

$x_{B}$ : displacement of poppet $\mathrm{B}, \mathrm{m}$

$x_{v m}:$ maximum displacement of the poppet, $\mathrm{m}$

$\phi_{v}:$ half angle of the poppet, rad

\section{Hydraulic-Brake Pressure Control Valve}

\subsection{Spool-type brake pressure control valve}

Figure 1 shows the schematic diagram of a spooltype brake pressure control valve. In the steady state, both supply and return ports are closed to maintain the output pressure $p_{b c}$. Under this condition, the forces acting on the spool (command force $F_{x}$, spring force, and feedback force) are balanced to hold the spool in the closed position. As the command force $F_{x}$ from an electrical control part increases, the spool moves forward against the feedback force; then the supply port opens to increase the output pressure. Since the output pressure is fed back to push the spool backward, the spool moves back, and the supply port is closed. If the output pressure exceeds the setting pressure, the feedback force pushes the spool backward to open the return port; this permits the flow to reduce the output pressure.

This type of pressure control valve is suitable in many applications. However, if this valve is used in the hydraulic brake system for railways, its internal leakage through radial clearance ${ }^{(14)}$ shown in Fig. 1 causes a loss of braking power when the power supply fails. Limitations on friction and manufacturing tolerance make it hard to reduce this clearance. In addition, attempts to reduce this leakage using methods such as designing a small overlap on the spool land cause hysteresis and other undesirable effects in the output characteristics.

\subsection{Poppet-type brake pressure control valve}

In order to solve the internal leakage problem of the

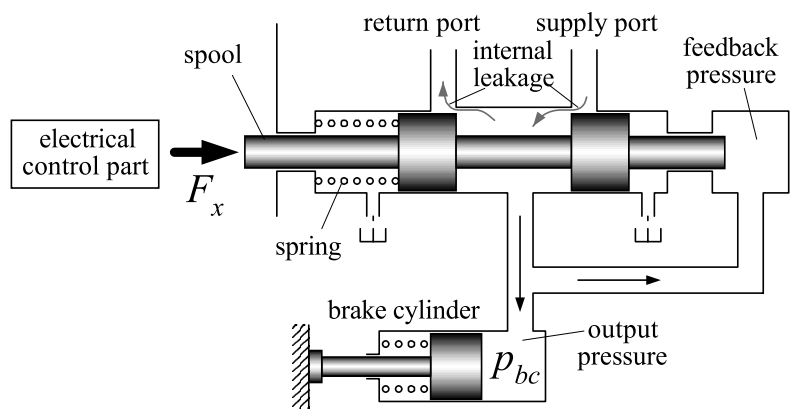

Fig. 1 Spool-type brake pressure control valve 


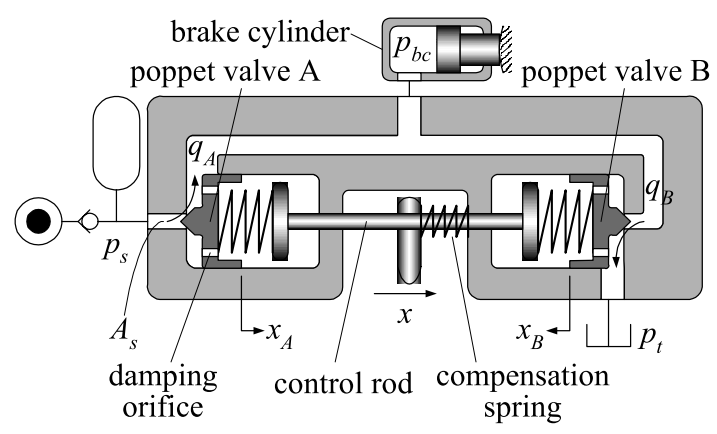

Fig. 2 Poppet-type brake pressure control valve

brake pressure control valve, poppet elements are adopted. When this type of valve is used in a servomechanism, it is necessary to consider the effects of flow force and the stability of the system ${ }^{(15)}$. However, these problems could be neglected in the developed valve because load flow in the brake control system is very small compared with general cases.

The schematic diagram of the developed poppet-type brake pressure control (BPC) valve is shown in Fig. 2. The structure is very simple considering maintenance and reliability. The BPC valve consists of two poppet valves where poppet valve A and poppet valve B are used to increase and to reduce the output pressure $p_{b c}$, respectively. The output pressure is proportional to the position of the control rod. Considering the stability of the valve, the flow through each poppet valve is designed to be in a diverging direction and the dampers are also designed on the poppet to increase stability.

The operating principle of the BPC valve is similar to the above spool-type valve. In the steady state, the closing force on poppet A by the output pressure and the spring is greater than the opening force by the supply pressure, and the closing force on poppet $\mathrm{B}$ by the return pressure and spring is greater than the opening force by the output pressure, then both valves close to hold the output pressure. If the displacement $x$ of the control rod is increased, the spring force on poppet $A$ is reduced whereas the spring force on poppet B is increased, hence, the setting value of the output pressure is increased. When the setting pressure is greater than the output pressure, valve $\mathrm{A}$ is opened to permit flow $q_{A}$ to increase the output pressure. The higher the output pressure, the greater the feedback force pushing poppet A to close the valve. When the output pressure is equal to the setting pressure, poppets A and B stop at the closed position to hold the output pressure. On the other hand, if $x$ is decreased, the spring force on poppet B is reduced, the setting pressure becomes less than the output pressure, then valve B is opened to permit flow $q_{B}$ to reduce the output pressure.

\section{Analysis and Compensation}

\subsection{Output pressure}

To analyze the above operating principle more precisely, the conditions for closing valve $\mathrm{A}$ and valve $\mathrm{B}$ $\left(x_{A}=0, q_{A}=0\right.$ and $\left.x_{B}=0, q_{B}=0\right)$ of the BPC valve are considered as follows.

When the characteristics of the springs in both valves are linear and identical and the return pressure $p_{t}$ is equal to 0 , the output pressure of the BPC valve can be written as Eq. (1).

$$
\frac{k_{s}}{A_{s}} x-\frac{k_{s} x_{0 A}-p_{s} A_{s}}{A_{s}}<p_{b c}<\frac{k_{s}}{A_{s}} x+\frac{k_{s} x_{0 B}}{A_{s}}
$$

In Eq. (1), the spring constant $k_{s}$, the cross-sectional area of the seat $A_{s}$, the initial lengths of the compressed springs $x_{0 A}$ and $x_{0 B}$, and the supply pressure $p_{s}$ are constant. Hence, the output pressure $p_{b c}$ is restricted to a constant range which is proportional to the $x$ of the control rod.

\subsection{Dead band of output pressure}

The output pressure in Eq. (1) can be rewritten as

$$
p_{b c}=\frac{k_{s}}{A_{s}} x+\Delta p_{b c}
$$

when the range of output error $\Delta p_{b c}$ is given by

$$
-\frac{\left(k_{s} x_{0 A}-p_{s} A_{s}\right)}{A_{s}}<\Delta p_{b c}<\frac{\left(k_{s} x_{0 B}\right)}{A_{s}}
$$

This range can be considered as a dead band around the setting pressure $\bar{p}_{b c}=\left(k_{s} / A_{s}\right) x$. It is found that a small dead band should be set to increase the stability of the BPC valve against pressure fluctuation in the pipes.

In order to set the dead band, $\tilde{x}_{0 A}$ and $\tilde{x}_{0 B}$ are defined as the initial lengths of the compressed springs when there is no dead band, and $x_{d z A}$ and $x_{d z B}$ are defined as the additional lengths for setting the lower boundary and the upper boundary of the dead band, respectively. Hence, the initial lengths of the compressed springs $x_{0 A}$ and $x_{0 B}$ can be written as

$$
\begin{aligned}
& x_{0 A}=\tilde{x}_{0 A}+x_{d z A} \\
& x_{0 B}=\tilde{x}_{0 B}+x_{d z B}
\end{aligned}
$$

where $\tilde{x}_{0 A}, \tilde{x}_{0 B}$ are given by

$$
\begin{aligned}
& \tilde{x}_{0 A}=\frac{p_{s} A_{s}}{k_{s}} \\
& \tilde{x}_{0 B}=0
\end{aligned}
$$

The range of output error after adjusting the initial lengths of the compressed springs and setting the dead band can be calculated from

$$
-\delta A<\Delta p_{b c}<\delta B
$$

where $\delta A$ and $\delta B$ are defined as

$$
\begin{gathered}
\delta A=\frac{k_{s} x_{d z A}}{A_{s}} \\
\delta B=\frac{k_{s} x_{d z B}}{A_{s}}
\end{gathered}
$$




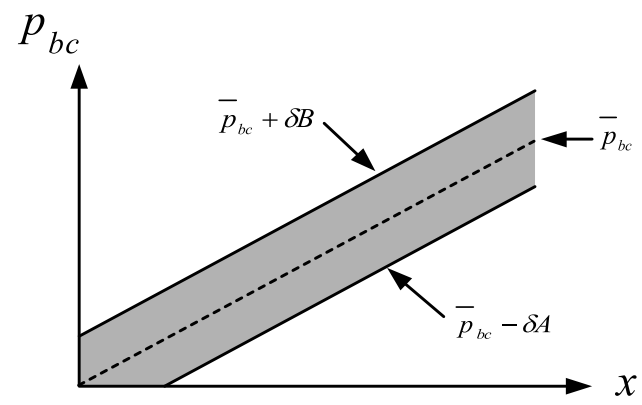

Fig. 3 Dead band of BPC valve

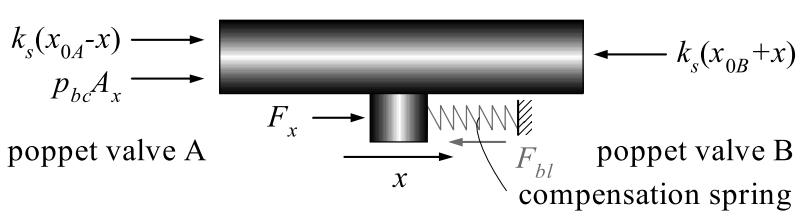

Fig. 4 Forces acting on control rod

From the above relations, the output pressure and the dead band can be shown as in Fig. 3. The output pressure is within the area between the lower boundary and the upper boundary of the dead band, which is proportional to the displacement $x$ with a gain of $k_{s} / A_{s}$.

\subsection{Operating force on control rod}

To conserve control energy and to guarantee braking in an unusual situation, the operating force of the BPC valve should be as small as possible, particularly when the electric power supply fails. For this purpose, the compensation spring shown in Figs. 2 and 4 is used to compensate the operating force.

In Fig. 4, friction and other forces can be ignored for simplicity, thus the force on the control rod is composed of spring forces $k_{s}\left(x_{0 A}-x\right), k_{s}\left(x_{0 B}+x\right)$, the feedback force $p_{b c} A_{x}$, the force of the compensation spring $F_{b l}$, and the operating force $F_{x}$. The balance of these forces can be expressed by

$$
p_{b c} A_{x}+k_{s}\left(x_{0 A}-x\right)+F_{x}=k_{s}\left(x_{0 B}+x\right)+F_{b l}
$$

When the dead band is close to zero $\left(\Delta p_{b c} \rightarrow 0\right)$, and $F_{x}^{\prime}$ is defined as the operating force before compensation, the operating force $F_{x}$ from Eq. (2), Eqs. (4) - (7), and Eq. (11) is given as

$$
\begin{aligned}
& F_{x}=F_{x}^{\prime}+F_{b l} \\
& F_{x}^{\prime}=-\left(A_{x} / A_{s}-2\right) k_{s} x-p_{s} A_{s} \\
& F_{b l}=k_{b l} x+F_{b l 0}
\end{aligned}
$$

where $k_{b l}$ and $F_{b l 0}$ are the spring constant and initial force of the compensation spring, respectively.

The relationship between $F_{x}^{\prime}$ and the displacement $x$ in Eq. (13) is shown in Fig. 5 (a), and the relationship between $F_{b l}$ and the displacement $x$ in Eq. (14) is shown in Fig. 5 (b). According to Eq. (12), the operating force required to maintain the position of the control rod can be determined by combining Fig. 5 (a) and (b). For example, if the cross-sectional area of the control $\operatorname{rod} A_{x}$ in

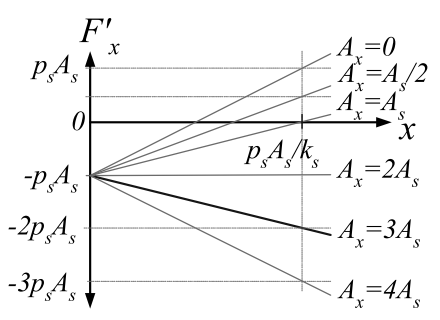

(a)

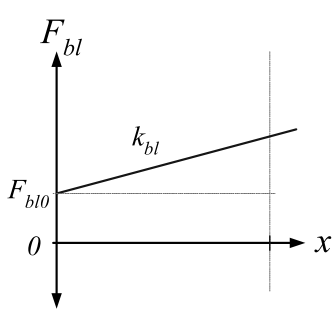

(b)
Fig. 5 Compensation of operating force at steady state

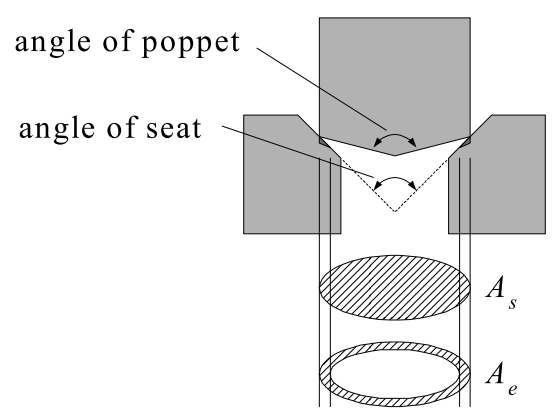

Fig. 6 Case 1: angle of seat $<$ angle of poppet

Fig. 5 (a) is larger than twice the cross-sectional area of the seat $\left(A_{x}>2 A_{s}\right)$, and the initial force and slope in Fig. 5 (b) are chosen as $F_{b l 0}=p_{s} A_{s}$ and $k_{b l}=\left(A_{x} / A_{s}-2\right) k_{s}$, respectively, the operating force $F_{x}$ will be 0 independent of the displacement $x$. This means that the BPC valve designed in this way does not require the operating force to maintain the pressure. Furthermore, if the initial force $F_{b l 0}$ in Fig. 5 (b) is decreased and the value of the spring constant $k_{b l}$ is raised, it is possible to set the displacement $x$ for which $F_{x}=0$. This means that it is possible to set a output pressure even when the operating force is zero.

\subsection{Compensation against wear}

The seat and poppet are subject to wear after being used for a long time. This causes changes in the setting value such as dead band and in the gain of the BPC valve. In order to compensate these changes, two models of poppet valves are considered.

Case 1: The angle of the seat is less than the angle of the poppet, as shown in Fig. 6.

Considering valve $\mathrm{A}$, the lower boundary of the output pressure can be given by

$$
p_{b c}>\frac{k_{s}}{A_{s}} x-\frac{k_{s} x_{0 A}-p_{s}\left(A_{s}-A_{e A}\right)}{A_{s}}
$$

and considering valve $\mathrm{B}$, the upper boundary can be given by

$$
p_{b c}<\frac{k_{s}}{A_{s}-A_{e B}} x+\frac{k_{s} x_{0 B}}{A_{s}-A_{e B}}
$$

where $A_{e A}$ and $A_{e B}$ are the changes in the cross-sectional area of the seat caused by wear.

If poppet valve $\mathrm{A}$ is designed in this way, the gain between the displacement $x$ and the output pressure $p_{b c}$ 


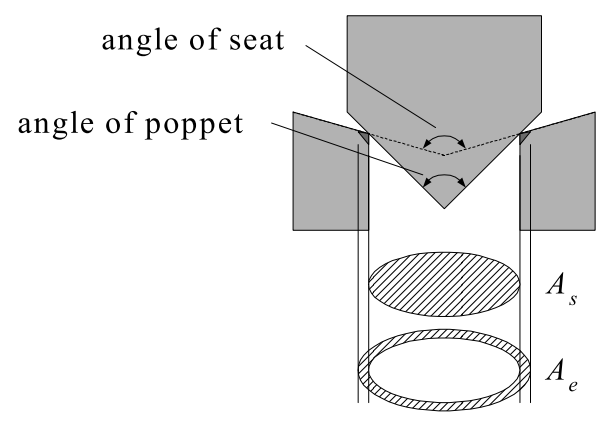

Fig. 7 Case 2: angle of seat $>$ angle of poppet

in Eq. (15) is independent of the change in cross-sectional area $A_{e A}$, and the effect of the change $A_{e A}$ on the dead-band can be compensated by adjusting the initial length of the compressed spring $x_{0 A}$. However, in this case the gain of valve $\mathrm{B}$ in Eq. (16) is increased by wear $\left(A_{s} \rightarrow A_{s}-A_{e B}\right)$.

Case 2: The angle of the seat is greater than the angle of the poppet, as shown in Fig. 7.

Considering valve A, the lower boundary of the output pressure can be given by

$$
p_{b c}>\frac{k_{s}}{A_{s}+A_{e A}} x-\frac{k_{s} x_{0 A}-p_{s} A_{s}}{A_{s}+A_{e A}}
$$

and considering valve $\mathrm{B}$, the upper boundary can be given by

$$
p_{b c}<\frac{k_{s}}{A_{s}} x+\frac{k_{s B} x_{0 B}}{A_{s}}
$$

In this case, the gain of valve B in Eq. (18) is independent of the change $A_{e B}$; however, the gain of valve $\mathrm{A}$ is affected by wear $\left(A_{s} \rightarrow A_{s}+A_{e A}\right)$ as shown in Eq. (17).

Consequently, in order to compensate for the change in characteristics with wear, it is suggested that poppet valve A should be designed as shown in case 1, and poppet valve B should be designed as shown in case 2 .

\section{Experiments}

Figure 8 shows the actual structure of the BPC valve and Table 1 shows the determined design parameters of the BPC valve. The diameter of the seat is designed to be $4 \mathrm{~mm}$ considering the proper transient response for the calliper brake of the E-2 series Shinkansen railway. In order to raise pressure control resolution, it is necessary to reduce the change in orifice opening area according to the poppet displacement. Accordingly, the half angle of the poppet is designed to be only $9.5^{\circ}$. In this valve, two springs (spring1 and spring2 in Fig. 8) are used. These springs are implemented in the precompressed state to ensure these linear operating range.

The experimental setup is shown in Fig. 9. As shown in Fig. 9, two adjustable orifices are inserted in the BPC valve in order to reduce the effects of surge and pulsating pressure. One is located between valve $\mathrm{A}$ and the brake cylinder, and the other is located between the brake cylinder and valve B. In the practical use of this BPC valve, a

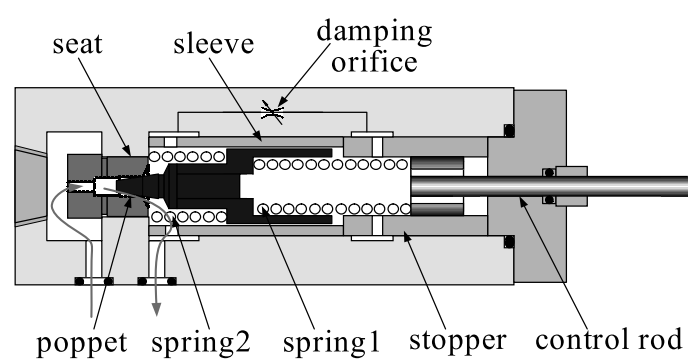

Fig. 8 Structure of poppet valve

Table 1 Design parameters of BPC valve

\begin{tabular}{|l||l|l||l|}
\hline$p_{s}$ & $12 \mathrm{MPa}$ & $k_{s 1}$ & $75 \mathrm{~N} / \mathrm{mm}$ \\
\hline$d_{v}$ & $4 \mathrm{~mm}$ & $k_{s 2}$ & $10 \mathrm{~N} / \mathrm{mm}$ \\
\hline$x_{v m}$ & $2 \mathrm{~mm}$ & $\phi_{v}$ & $9.5^{\circ}$ \\
\hline
\end{tabular}

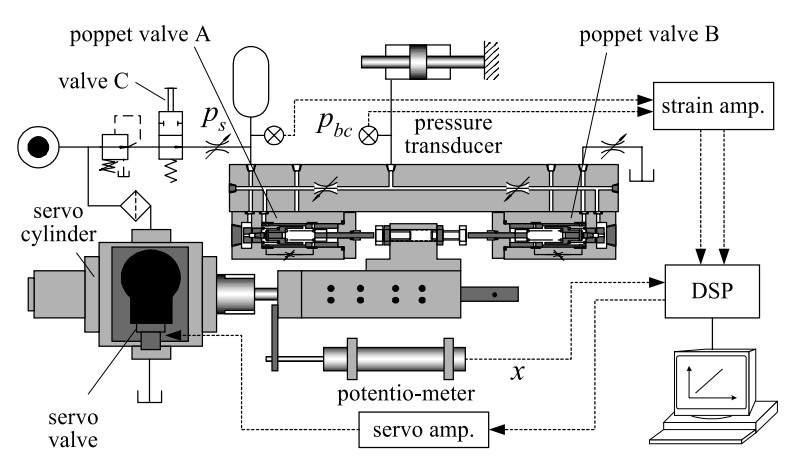

Fig. 9 Experimental setup

stepping motor would be the best candidate for driving the control rod of the BPC valve. In this experiment, the control rod of the BPC valve is controlled by a servo cylinder, which is commanded by a set of a computer and a DSP unit. To eliminate the effects of the initial gap and bending of the actual calliper, a fixed-volume cylinder chamber is used. The volume of this chamber is fixed at $40 \mathrm{~cm}^{3}$, the same as the volume in the actual calliper brake.

In order to tune the dead band of the output pressure, the initial lengths of the compressed springs are adjusted by the screw which can be found on the control rod of the BPC valve. The initial values and the direction can be determined based on Eqs. (6) - (8). The dead-band is tuned so that the output error is as small as possible, and the system is also stable. Figure 10 shows the measured dead band, which is obtained from the cracking pressure of each poppet. From the experimental results it can be known that the response characteristics of the two poppets are very linear and the dead band is quite small.

The relationship between the displacement of the control rod and the output pressure is obtained as shown in Fig. 11. The results are linear and have almost no hysteresis. As expected, all of the outputs are in the dead 


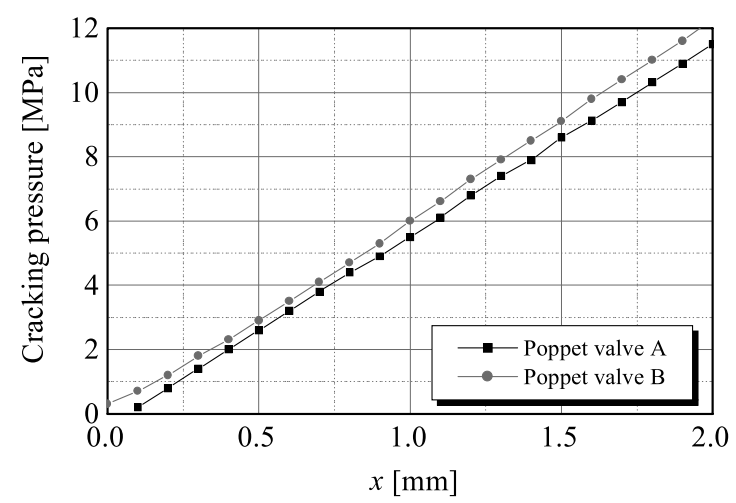

Fig. 10 Cracking pressure of each poppet valve

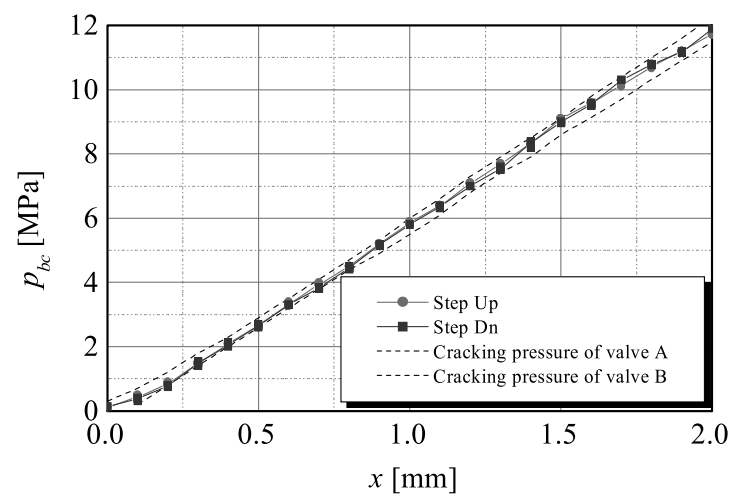

Fig. 11 Static characteristic of BPC valve

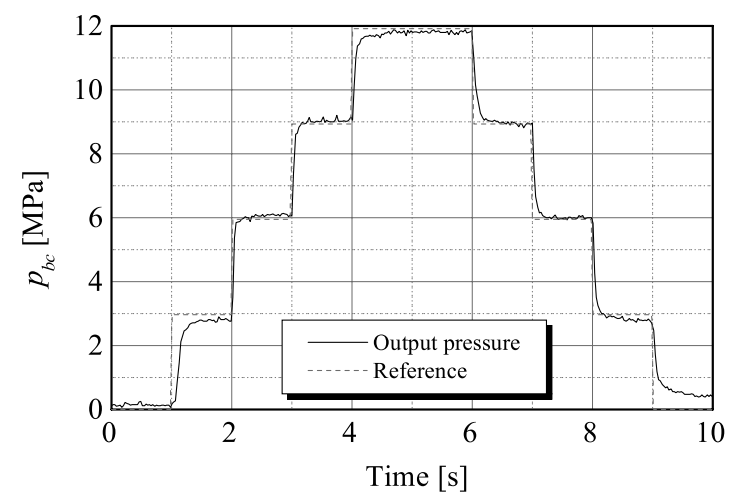

Fig. 12 Step input experimental result

band, and it is identified that these characteristics are almost identical through the five experiments.

The transient response characteristics and stability of the BPC valve are examined by the step input with a fixed step (3, 6, 9 and 12 MPa). The result in Fig. 12 shows that the output pressure is stable at all input pressures. Although the output pressure characteristics with respect to the reference input of the low-pressure range ( $3 \mathrm{MPa}$ ) and high-pressure range (12 $\mathrm{MPa})$ show a relatively large steady-state error, it is considered that these are caused by manufacturing problems such as the mismanagement of spring end faces. The response is much faster than that of the pneumatic brake system, which has a settling time of more than $1 \mathrm{sec}$. Since the poppet of the BPC valve is

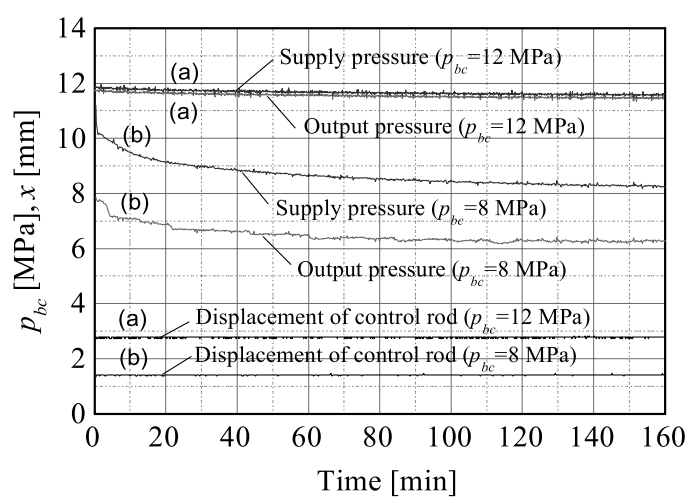

Fig. 13 Experimental result of leakage test

supported with a spring, there could be a stability problem. However, it is identified from the experiment that when the spring constant is large, pressure fluctuation did not occur and the response converged at the target pressure well. It is also identified that by virtue of setting the damping orifice to be large, it is possible to obtain a fast and stable pressure response like that shown in Fig. 12. When the spring constant is small, the stability of the valve decreases and pressure fluctuation occurs. In this instance, it is necessary to set the damping orifice to be small in order to keep pressure fluctuation at a minimum. Consequently, the pressure response come to be slow. In this research, a spring with a large spring constant is used. (Note that details of the dynamic behavior and the stability of the system will be analyzed and described in a subsequent publication - part II.)

In order to apply the BPC valve to the hydraulic brake system of the railway, the internal leakage characteristic of the BPC valve is investigated. Figure 13 shows the experimental results of two types of leakage test. The experimental result (a) in Fig. 13 shows the performance of maintaining the output pressure at a maximum value (12 MPa) under the condition that external energy is not supplied to the hydraulic system and control valve. In the experiment, by virtue of closing valve C (in Fig. 9), the power supply is shut down. The energy source is only a one-litre accumulator. The output pressure is measured for $160 \mathrm{~min}$. In this experiment, the compensation spring is selected so that the displacement of the control rod can be more than $2 \mathrm{~mm}$ even though the operating force has a maximum at $2 \mathrm{~mm}$. This is to guarantee a proper closing force against disturbance at valve $\mathrm{B}$. The experimental results show that the output pressure can be maintained at a sufficiently high value though a small decrement is observed. This verifies that by virtue of setting the valve this way, the braking force can be maintained if the electric power supply fails.

The experimental result (b) in Fig. 13 shows the performance of maintaining the output pressure at $8 \mathrm{MPa}$ (the displacement of the control rod is $1.3 \mathrm{~mm}$ ). Although the 
output pressure decreases gradually, the reduction rate decreases and converges to zero. This is because the decrease in output pressure is caused by the leakage due to the insufficient closing force applied to valve B. However, the higher the output error, the higher the closing force on valve B. That is, if the output pressure decreases by leakage and reaches a value lower than the lower boundary of the dead band, poppet A opens to permit flow from the accumulator to compensate for the output pressure. Thus, the supply pressure in the accumulator decreases gradually as in Fig. 13. According to Eq. (1), the setting pressure $\left(\left(k_{s} / A_{s}\right) x\right)$ and the upper boundary of the dead band $\left(\left(k_{s} / A_{s}\right) x+\left(k_{s} / A_{s}\right) x_{0 B}\right)$ are independent of the supply pressure, but the lower boundary of the dead band $\left(\left(k_{s} / A_{s}\right) x-\left(k_{s} / A_{s}\right) x_{0 A}+p_{s}\right)$ decreases according to the supply pressure $p_{s}$. Therefore, the output pressure and the lower boundary of the dead band decrease simultaneously due to the leakage from valve $\mathrm{B}$, whereas this leakage decreases gradually according to the increment in output error and the closing force applied to valve $\mathrm{B}$. The above results demonstrate the validity of the fail-safe features of the BPC valve. Therefore, in an emergency case such as power supply failure, if the BPC valve is adjusted to maintain a certain specific pressure, the maximum pressure loss of the system will be approximately $2 \mathrm{MPa}$. However, in the emergency, if the BPC valve is used to maintain the maximum pressure, then, there will be almost no energy loss due to internal leakage.

\section{Conclusions}

In order to realize a hydraulic brake system for the railway, a poppet-type brake pressure control valve (BPC valve) is developed. As the internal leakage is extremely small, this valve can maintain the pressure when the power supply fails. Moreover, by designing a built-in pressure feedback mechanism inside this valve, the pressure can be controlled even when the pressure transducer is broken. The static characteristics of this valve, the methods of compensating the operating force and the characteristic change due to the wear of poppet elements are investigated. Through the experiments such as the dead band, displacement-pressure characteristic and leakage characteristic, the validity of the design of this valve is confirmed.

\section{Acknowledgements}

The authors would like to thank to Dr. Sumio Arai,
Dr. Toshio Kaneko, Kayaba Ltd., Co., and the Railway Technical Research Institute for their grateful information and technical support.

\section{References}

( 1 ) Leigh, M.J., Brake Blending, Proc. Instn. Mech. Engrs., Part F, Journal of Rail and Rapid Transit, Vol.208 (1994), pp.43-49.

( 2 ) Marsh, G.H. and Sharp, A.C., The Development of Railway Brakes (Part 1: 1730-1880), The Railway Engineering Journal, Vol.1 (1973), pp.46-53.

( 3 ) Marsh, G.H. and Sharp, A.C., The Development of Railway Brakes (Part 2: 1880-1940), The Railway Engineering Journal, Vol.3 (1973), pp.32-42.

( 4 ) Sharp, A.C., Railway Braking: A History, Engineering, Vol.219, No.3 (1979), pp.1112-1122.

( 5 ) Walley, D.M., Development of Reliability Engineering on Britain's Railways, Design, IMechE Seminar Publication on Reliability, and Maintenance for Railways, London, IMechE Seminar Publication 1996-18, Paper C511/3/000/96, pp.21-33.

( 6 ) Uesugi, T., Kawaguchi, K. and Watanabe, T., Behavior of Adhesion for Braking on Series 681 EMU, RTRI Report, (in Japanese), Vol.13, No.10 (1999), pp.19-24.

( 7 ) Ohyama, T., Adhesion Characteristics of Wheel/Rail System and Its Control at High Speeds, Quarter Report of RTRI, Vol.33, No.1 (1992), pp.19-30.

( 8 ) Nielsen, J.C.O. and Johansson, A., Out-of-Round Railway Wheels-a Literature Survey, Proc. Instn. Mech. Engrs., Part F, Journal of Rail and Rapid Transit, Vol.214 (2000), pp.79-91.

( 9 ) Westinghouse Air Brake Co., The "AB" Freight Brake Equipment, Instruction Pamphlet of Westinghouse Air Brake Company No.5062 (1945), pp.1-65.

(10) Vieten, K.W., High Performance Fighter Fly-By-Wire Flight Control Actuation System, AIAA Aerospace Design Conference, AIAA 92-1123, (1992), pp.1-11.

(11) Brock, L.D. and Goddman, H.A., Reliability/Safety Analysis of a Fly-by-Wire System, AIAA Guidance and Control Conference, AIAA 80-1760, (1980), pp.276-282.

(12) Kaneko, T., Research on Brake Equipments for the Railway, Trans. of the JSME, (in Japanese), Vol.44, No.379 (1978), pp.907-915.

(13) Uchida, S. and Kumagai, N., Development of Hydraulic Brake for Rolling Stock, RTRI Report, (in Japanese), Vol.12, No.1 (1998), pp.1-6.

(14) Merrit, H.E., Hydraulic Control Systems, (1967), John Wiley \& Sons, New York.

(15) Blackburn, J.F., Reethof, G. and Shearer, J.L., Fluid Power Control, (1960), MIT Press, U.S.A. 